\title{
Sedimentary Coprostanol in Kaohsiung Harbour and the Tan-Shui Estuary, Taiwan
}

\author{
WOEI-LIH JENG* and BOR-CHENG HAN $\dagger$ \\ *Institute of Oceanography, National Taiwan University, Taipei, Taiwan \\ † School of Public Health, Taipei Medical College, Taipei, Taiwan
}

Coprostanol in sediments from Kaohsiung Harbour and the Tan-Shui Estuary has been analysed. In the Kaohsiung Harbour sediments, coprostanol has a concentration range between 0.58 and $128 \mu \mathrm{g} \mathrm{g}^{-1}$ dry wt with a mean of $20.8 \mu \mathrm{g} \mathrm{g}^{-1}$ dry wt; higher concentrations are found near the mouths of rivers. Moreover, a significant $\log -\log$ correlation is found between total coprostanol concentration and oil hydrocarbon concentration $\left(r=0.803^{*}\right)$. In Tan-Shui Estuary sediments, coprostanol ranges in concentration from 1.00 to $230 \mu \mathrm{g} \mathrm{g} \mathrm{g}^{-1}$ dry wt with an average of $63.5 \mu \mathrm{g} \mathrm{g}^{-1} \mathrm{dry}$ wt; relatively high levels of coprostanol $\left(>10 \mu \mathrm{g} \mathrm{g}^{-1}\right.$ ) with $5 \beta / 5 \beta+5 \alpha$ cholestanol ratios $>0.7$ indicate positive sewage pollution. This probably results from an input from the sewage outfall, anoxicity, shallow water depths, inadequate tidal flushing, etc. Additionally, highly significant correlations have been found for coprostanol and cholesterol $\left(r=0.986^{*}\right)$ and for cholestanol and cholesterol $\left(r=0.981^{*}\right)$; these relationships are thought to be mediated predominantly by sediment micro-organisms in the reducing environment.

Studies on coprostanol have dealt primarily with its content in water and sediment as an indicator of sewage pollution (Goodfellow et al., 1977; Hatcher \& McGillivary, 1979; McCalley et al., 1980; Yde et al., 1982; Brown \& Wade, 1984; Dureth et al., 1986; Grimalt et al., 1990; Venkatesan \& Kaplan, 1990; LeBlanc et al., 1992). The distribution of coprostanol in surface sediments showed a progressive decline from sewage outfalls in an ocean basin (Venkatesan \& Kaplan, 1990) and from the head of a bay (LeBlanc et al., 1992). Coprostanol has been shown to be a reliable marker of sewage pollution when coliform bacteria may have been destroyed due to high temperatures or the presence of toxic substances (Churchland et al., 1982; Yde et al., 1982; Dureth et al., 1986). It has been demonstrated that coprostanol will degrade during aerobic wastewater treatment processes (McCally et al., 1981 ) or when incubated with bacteria isolated from lake water (Switzer-Howse \& Dutka, 1978). However, studies have shown that coprostanol, together with cholesterol and cholestanol, was very persistent in anoxic sediments (Nishimura \& Koyama, 1977; Hatcher \& McGillivary, 1979; Venkatesan et al., 1986; Bartlett, 1987; LeBlanc et al., 1992). Coprostanol has also been used to show sewage pollution history from a dated sediment core (Muller et al., 1979).

Jeng \& Han (1991) made a preliminary survey of sedimentary coprostanol concentrations along the western Taiwan coast, found Kaohsiung Harbour (six data) and the Tan-Shui Estuary (four data) to be hot spots, and concluded coprostanol levels reflecting population distribution with no further discussion. Kaohsiung Harbour, situated on the southwestern coast, is the largest commercial port in Taiwan and has heavy tanker traffic and operations, other ship traffic, and industrial activities. The harbour has been polluted by heavy metals (Chen, 1977). Thirteen sediment samples were taken from the channel (depth 10-14 m), and the sampling sites are shown in Fig. 1. The Tan-Shui Estuary, located on the outskirts of Taipei city, northern Taiwan, has also been heavily polluted by heavy metals- $\mathrm{Cu}, \mathrm{Zn}, \mathrm{Pb}$, and $\mathrm{Cd}$ (Tseng, 1991). The estuary is very anoxic, the dissolved oxygen of which is virtually zero. The water depth of the estuary is generally about $2 \mathrm{~m}$ although the maximum depth may be over $10 \mathrm{~m}$. Fifteen sediment samples were collected; the sampling stations are given in Fig. 2.

The purposes of this study were: 1 . to determine the distribution of coprostanol in anoxic sedimentary environments-harbour and estuary were untreated and/or treated sewage are discharged into these areas; 2. to examine the relationship among coprostanol (5 3 cholestanol), cholesterol, and cholestanol (5acholestanol) in the anoxic sediments; and 3. to see if coprostanol is correlated with oil hydrocarbons in harbour sediments with heavy tanker and ship traffic influence.

\section{Methods and Materials}

Sediment samples were collected with a gravity corer having a $6 \mathrm{~cm}$ diameter core barrel. The top $5 \mathrm{~cm}$ sediment was separated and stored frozen until 


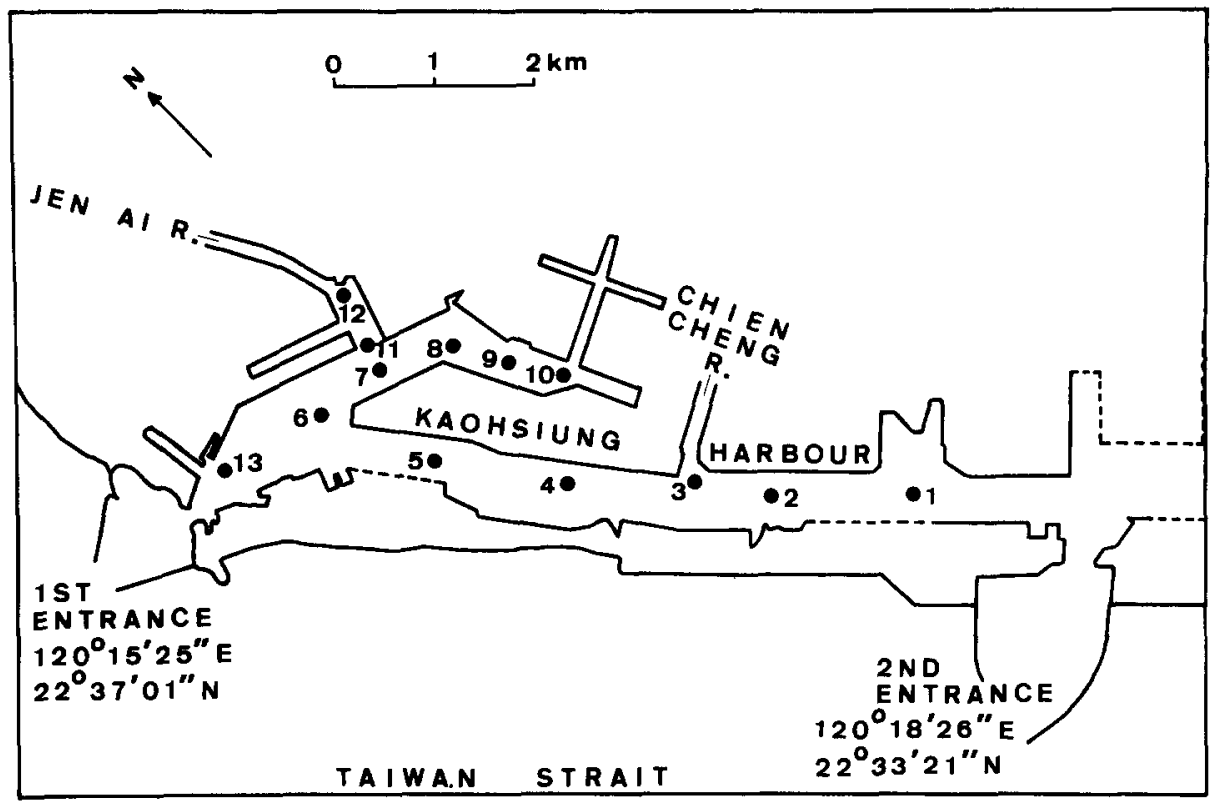

Fig. 1 Location of sampling sites in Kaohsiung Harbour.

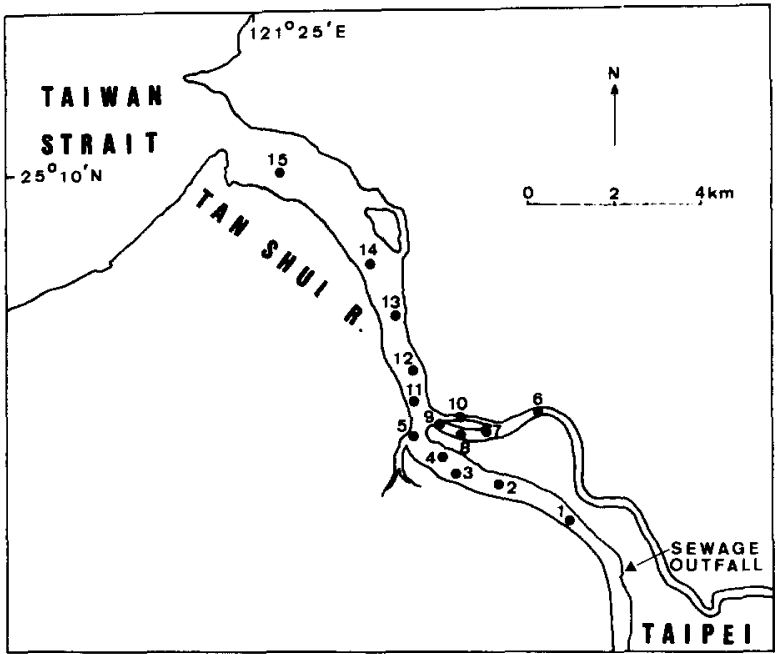

Fig. 2 Location of sampling sites in the Tan-Shui Estuary.

required. After the addition of 1-nonadecanol as the internal standard, the freeze-dried sediment was Soxhlet-extracted with a 1:1 mixture of benzene and methanol for $24 \mathrm{~h}$. The extract was saponified with 0.5 $\mathrm{N}$ methanolic $\mathrm{KOH}$; the non-saponified fraction was isolated by hexane extraction four times. The hexane extract was dried and fractionated by column chromatography on silica gel (containing 5\% water). Elution with n-hexane gave aliphatic hydrocarbons which were generally referred to as 'oil hydrocarbons' (Readman et al., 1986), the less polar lipids were removed by elution with $40 \%$ hexane in chloroform, and the alcohols/sterols-containing fraction was isolated using $10 \%$ methanol in chloroform. The last fraction was dried and then converted to trimethylsilyl ether derivatives using NO-Bis (trimethylsilyl) acetamide.

Sterols (as TMS ethers) were analysed with an HP 5890A gas chromatograph equipped with a split/ splitless injector and an FID. An OCI-5 cool oncolumn injector (SGE, Australia) was also fitted in the chromatograph for quantitation. A $30 \mathrm{~m} \times 0.25 \mathrm{~mm}$ i.d. fused silica column coated with SE-30 was used for analysis. A three-ramp temperature programme was employed: $45-90^{\circ} \mathrm{C}$ at $15^{\circ} \mathrm{C} \min ^{-1} ; 90-270^{\circ} \mathrm{C}$ at $3^{\circ} \mathrm{C}$ $\min ^{-1}$ with a holding time of $20 \mathrm{~min}$ at $270^{\circ} \mathrm{C}$; and $270-280^{\circ} \mathrm{C}$ at $10^{\circ} \mathrm{C} \mathrm{min}{ }^{-1}$ with a holding time of 20 min at $280^{\circ} \mathrm{C}$. Hydrogen was used as the carrier gas. Identification was made by co-injection with authentic standards. Selected samples were positively identified with an HP 5970B Mass Selective Detector. Peak areas of gas chromatograms were integrated with a Shimadzu data processor, Chromatopac C-R6A. Quantitation was achieved by comparison of sample peak areas with the peak areas of the internal standard, 1-nonadecanol. The precision of the method was determined by five replicate analyses of the same sediment sample, and the relative standard deviation was $2.1 \%$.

Oil hydrocarbons are a complex mixture containing normal, branched and cyclic alkanes. They can be analysed by gas chromatography (GC) or by infrared spectroscopy (IR). GC is a detailed characterization technique which separates individual normal and branched alkanes with the presence of an unresolved complex mixture (UCM) by using high resolution capillary columns, identifies them if coupled with mass spectrometry, and quantifies them (Readman et al., 1986). IR, however, is a gross characterization technique which is based on optical density measurements of the aliphatic hydrocarbon fraction at the $\mathrm{CH}_{3}$, $\mathrm{CH}_{2}$ and $\mathrm{CH}$ stretching frequencies in the region of $3.40 \mu \mathrm{m}$ (Simard et al., 1951). Basically, the two techniques measure the same group of aliphatic hydrocarbons. However, IR has the advantage of being simple, easy and quick.

The oil hydrocarbon fraction was passed through a short column of activated copper. The eluate was dried and redissolved in $\mathrm{CCl}_{4}$. The oil hydrocarbon concentrations were quantitated with a MIRAN-1A infrared analyser (Foxboro, USA) by using a $1 \mathrm{~cm}$ pathlength cell and by measuring stretching frequency 
at $3.40 \mu \mathrm{m}$. Several appropriate dilutions prepared from an artificial oil hydrocarbon standard, $\mathrm{n}$-hexadecane-isooctane-chlorobenzene $(3: 3: 2, \mathrm{v} / \mathrm{v} / \mathrm{v})$ were used to construct the working curves. The relative standard deviation of the method was $6.1 \%$ (four replicates).

$E_{\mathrm{h}}$ was measured in situ right after sample collection using a combined reference $(\mathrm{Ag} / \mathrm{AgCl})$ and platinum electrode. The reading was taken after a period of $60 \mathrm{~s}$ for the electrode to reach a steady potential.

All solvents used were HPLC grade, and all reagents employed were reagent grade.

\section{Results and Discussion}

Coprostanol and epicoprostanol are faecal sterols, and their relative distributions may vary with animal (Venkatesan \& Santiago, 1989). These two faecal sterols have been found in sewage effluents, for example, from the sewage outfall in the Tan-Shui Estuary and from that in southern California (Venkatesan \& Kaplan, 1990) since they are contained in human faeces (Eneroth et al., 1964). Therefore, coprostanol and epicoprostanol are summed up to represent the total amount of faecal sterols. Data for sterols and oil hydrocarbons in the Kaohsiung Harbour sediments are presented in Table 1. Concentrations of total coprostanol show a wide range $0.58-128 \mu \mathrm{g} \mathrm{g}^{-1}$ dry wt (mean $20.8 \mu \mathrm{g} \mathrm{g}^{-1}$ ) which is comparable to that found in sediments from the canals and lagoon of Venice, Italy (Van Vleet et al., 1988). Their coprostanol concentrations ranged from 0.2 to $40.9 \mu \mathrm{g} \mathrm{g}^{-1}$; the highest concentration was found in the interior canals. Higher values in Kaohsiung Harbour are found at stations $2,3,11$ and 12 , since they are located near the river mouths where some untreated sewage from Kaohsiung city is discharged into the harbour. The coprostanol/epicoprostanol ratio can be an indicator of different animal sources; for human pollution in Santa Monica Basin, the ratio has a range of 1.5-2.8 with an average of 2.1 (Venkatesan \& Santiago, 1989). The coprostanol/epicoprostanol ratios of Kaohsiung
Harbour range from 1.6 to 6.0 with a mean of 3.4 . Grimalt et al. (1990) concluded that the $5 \beta / 5 \beta+5 \alpha$ cholestanol ratios between 0.7 and 1 are characteristic of urban sewage pollution. It is noted, however, that the $5 \beta / 5 \beta+5 \alpha$ cholestanol ratios of the Kaohsiung Harbour sediments are all below 0.7 (average 0.5). They suggested using the $5 \beta / 5 \beta+5 \alpha$ cholestan-3-one ratio for the reliable identification of sewage pollution in moderately polluted samples (characteristic coprostanol concentration on the order of $\mu \mathrm{g} \mathrm{g}^{-1}$ or below). We did not investigate sterones; therefore, no further discussion can be made. In addition, the harbour sediments have been found to contain high levels of oil hydrocarbons (Table 1). It is of special interest to see if two different classes of pollutants, coprostanol and oil hydrocarbons, are correlated. Having performed linear regression on a plot of $\log ($ oil hydrocarbons) against $\log (\Sigma$ coprostanol), we obtain

$\log ($ oil hydrocarbons $)=0.374 \log \left(\sum\right.$ coprostanol $)+3.20$, with a linear correlation coefficient of $0.803(p<0.05)$, indicating a significant correlation (Fig. 3). Five other

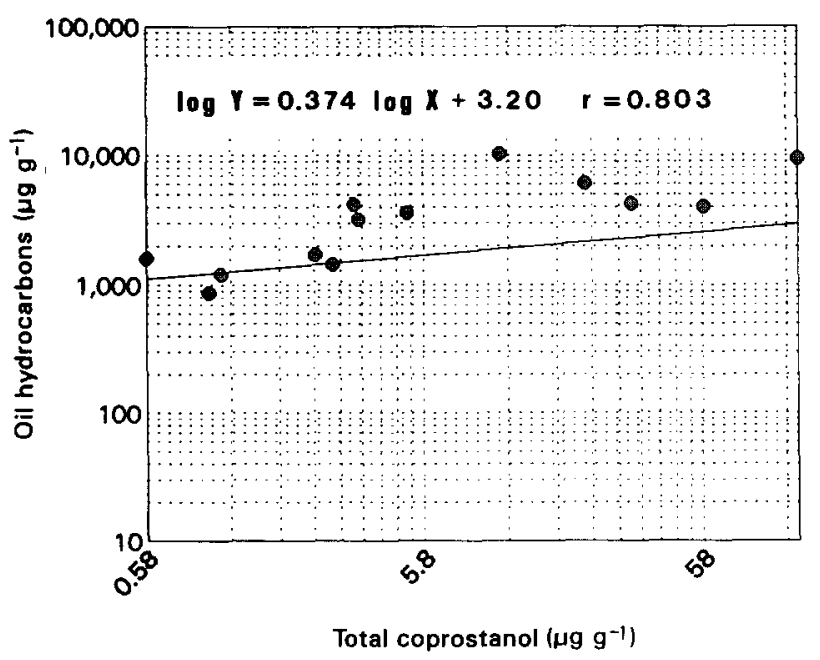

Fig. 3 Plot of oil hydrocarbons vs total coprostanol in sediments from Kaohsiung Harbour.

TABLE 1

Data for sterols and oil hydrocarbons measured in sediments from Kaohsiung Harbour.

\begin{tabular}{|c|c|c|c|c|c|c|c|c|}
\hline $\begin{array}{l}\text { Station } \\
\text { No. }\end{array}$ & $\begin{array}{l}\text { Coprostanol } \\
\left(\mu \mathrm{g} \mathrm{g}^{-1}\right)\end{array}$ & $\begin{array}{l}\text { Epicoprostanol } \\
\left(\mu g^{-1}\right)\end{array}$ & $\begin{array}{c}\text { Cholesterol } \\
\left(\mu \mathrm{g} \mathrm{g}^{-1}\right)\end{array}$ & $\begin{array}{c}\text { Cholestanol } \\
\left(\mu \mathrm{g} \mathrm{g}^{-1}\right)\end{array}$ & $\begin{array}{c}\Sigma \text { Coprostanol } \\
\left(\mu \mathrm{g} \mathrm{g}^{-1}\right)\end{array}$ & $\frac{\text { Cop. }}{\text { E-cop. }}$ & $r^{*}$ & $\begin{array}{l}\text { Oil HCt } \\
\left(\mu g^{-1}\right)\end{array}$ \\
\hline 1 & 1.49 & 0.85 & 4.06 & 3.06 & 2.34 & 1.8 & 0.43 & 1720 \\
\hline 2 & 19.8 & 12.4 & 42.6 & 16.7 & 32.2 & 1.6 & 0.69 & 4260 \\
\hline 3 & 35.9 & 22.3 & 34.5 & 22.5 & 58.2 & 1.6 & 0.51 & 4010 \\
\hline 4 & 1.73 & 0.98 & 3.46 & 2.41 & 2.71 & 1.8 & 0.53 & 1440 \\
\hline 5 & 2.26 & 1.11 & 4.82 & 4.11 & 3.37 & 2.0 & 0.45 & 3210 \\
\hline 6 & 0.80 & 0.27 & 2.31 & 1.44 & 1.07 & 3.0 & 0.43 & 1210 \\
\hline 7 & 4.13 & 0.93 & 6.45 & 4.83 & 5.06 & 4.4 & 0.49 & 3600 \\
\hline 8 & 9.27 & 1.64 & 15.1 & 8.58 & 10.9 & 5.7 & 0.56 & 10300 \\
\hline 9 & 2.56 & 0.69 & 4.69 & 4.28 & 3.25 & 3.7 & 0.43 & 4210 \\
\hline 10 & 0.82 & 0.15 & 1.56 & 0.90 & 0.97 & 5.5 & 0.52 & 869 \\
\hline 11 & 110 & 18.3 & 47.7 & 68.8 & 128 & 6.0 & 0.65 & 9490 \\
\hline 12 & 18.1 & 3.88 & 14.5 & 27.0 & 22.0 & 4.7 & 0.45 & 6070 \\
\hline 13 & 0.42 & 0.16 & 1.04 & 0.81 & 0.58 & 2.6 & 0.42 & 1610 \\
\hline Average & & & & & 20.8 & 3.4 & 0.50 & 4000 \\
\hline
\end{tabular}

${ }^{*} r=5 \beta / 5 \beta+5 \alpha=\Sigma$ coprostanol $/(\Sigma$ coprostanol + cholestanol $)$.

$\dagger$ Oil $\mathrm{HC}=$ oil hydrocarbons. 
sediment samples collected from Keelung Harbour, northern Taiwan have the following data:

\begin{tabular}{lrrrrc} 
Sample & A & B & C & D & E \\
\hline$\Sigma$ Coprostanol $\left(\mu \mathrm{g} \mathrm{g}^{-1}\right)$ & 140 & 114 & 13.4 & 0.9 & 1.9 \\
Oil hydrocarbons $\left(\mu \mathrm{g} \mathrm{g}^{-1}\right)$ & 3210 & 7320 & 1310 & 442 & 570
\end{tabular}

Using the same plot, the regression equation derived from these data is:

$\log ($ oil hydrocarbons $)=0.486 \log (\Sigma$ coprostanol $)+2.64$,

which has a good linear correlation $\left(r=0.958^{*}\right)$. However, Van Vleet et al. (1988) found that hydrocarbon contamination was only weakly correlated with coprostanol concentrations $(r=0.48)$.

The present result of a significant correlation between coprostanol and oil hydrocarbons is of interest. The sorption process of nonpolar organic compounds on sediments may play an important role. These two compound classes are neutral and highly hydrophobic. The sorption of hydrophobic molecules is determined by the organic carbon content of the substrate (Karickhoff et al., 1979; Means et al., 1980). The sorption constant $K_{\mathrm{oc}}$ is derived from

$$
K_{\mathrm{oc}}=\frac{K_{\mathrm{p}}}{\% O C},
$$

where $K_{\mathrm{p}}$ is the linear partition coefficient and $O C$ is the organic carbon content of the sorbent. $K_{\mathrm{p}}$ is represented by

$$
K_{\mathrm{p}}=\frac{C_{\mathrm{s}}}{C_{\mathrm{w}}}
$$

where $C_{s}$ is the equilibrium concentration of the compound sorbed to the solid phase and $C_{\mathrm{w}}$ is the concentration of the compound remaining in the aqueous phase at equilibrium. By using equations (1) and (2), it can be shown that for two compounds sorbed to a sediment in the batch equilibrium sorption experiment, the ratio of two compounds in sediment is proportional to that in solution. By inference, in natural systems such as a harbour, two compounds (or two compound classes) sorbed to sediments would be correlated provided their relative concentrations in water vary within a very narrow range or are constant and the equilibrium between sediment and water solution has been approached or reached. For Kaohsiung Harbour, it might imply that the harbour water is comparatively well mixed with respect to coprostanol and oil hydrocarbons.

Sterol levels in surface sediments from the Tan-Shui Estuary are given in Table 2. The three highest values are found at stations $3-5$, showing that coprostanol discharged from the sewage outfall tends to accumulate there. Apparently, coprostanol, most of which ( $>91 \%)$ was associated with particulates in the effluent, in the suspended particles from the sewage outfall travelled a very short distance probably due mainly to shallow water depths (ca. $2 \mathrm{~m}$ ) and was deposited at stations 35. This result may also reflect inadequate tidal flushing which helps to build up coprostanol in sediments. The concentration range of total coprostanol is $1.00-230 \mu \mathrm{g}$ $\mathrm{g}^{-1}$ dry wt, the average being $63.5 \mu \mathrm{g} \mathrm{g}^{-1}$ which is higher than that of Kaohsiung Harbour, $20.8 \mu \mathrm{g} \mathrm{g}^{-1}$. The coprostanol/epicoprostanol ratios have a range of $1.8-8.8$ with an average of 3.1 which is close to that of Kaohsiung Harbour. Twelve out of fifteen samples have $5 \beta / 5 \beta+5 \alpha$ ratios $>0.7$ indicating positive sewage pollution (Grimalt et al., 1990).

From visual observation Tan-Shui Estuary sediments were black in colour and had $\mathrm{H}_{2} \mathrm{~S}$ odour, and $E_{\mathrm{h}}$ values were generally negative (see Table 2), meaning that the sediments were in the anoxic environment. It is expected that cholesterol must have gone through some degree of diagenetic transformation. In order to test this idea, we have performed linear regression on coprostanol vs cholesterol and cholestanol vs cholesterol. It is clearly seen from Figs 4 and 5 that linear correlations are highly positive, suggesting that coprostanol, cholesterol, and cholestanol may approach or close to a 'similar' degree of cholesterol transformation. The microbial transformation of cholesterol into coprostanol and cholestanol has been studied in a number of different sedimentary environments (Gaskell \&

TABLE 2

\begin{tabular}{|c|c|c|c|c|c|c|c|c|}
\hline $\begin{array}{l}\text { Station } \\
\text { No. }\end{array}$ & $\begin{array}{l}\text { Coprostanol } \\
\left(\mu \mathrm{g} \mathrm{g}^{-1}\right)\end{array}$ & $\begin{array}{l}\text { Epicoprostanol } \\
\quad\left(\mu \mathrm{g} \mathrm{g}^{-1}\right)\end{array}$ & $\begin{array}{l}\text { Cholesterol } \\
\qquad\left(\mu \mathrm{gg}^{-1}\right)\end{array}$ & $\begin{array}{c}\text { Cholestanol } \\
\left(\mu \mathrm{gg}^{-1}\right)\end{array}$ & $\begin{array}{c}\Sigma \text { Coprostanol } \\
\left(\mu \mathrm{g} \mathrm{g}^{-1}\right)\end{array}$ & $\frac{\text { Cop. }}{\text { E-cop. }}$ & $r^{*}$ & $\begin{array}{c}\mathrm{E}_{\mathrm{h}} \\
(\mathrm{mv})\end{array}$ \\
\hline 1 & 33.3 & 3.80 & 24.1 & 8.54 & 37.1 & 8.8 & 0.81 & -493 \\
\hline 2 & 42.9 & 15.0 & 32.0 & 13.0 & 57.9 & 2.9 & 0.82 & -134 \\
\hline 3 & 163 & 67.4 & 79.1 & 46.6 & 230 & 2.4 & 0.83 & -478 \\
\hline 4 & 101 & 36.6 & 54.0 & 28.7 & 138 & 2.8 & 0.86 & -5 \\
\hline 5 & 121 & 41.0 & 64.8 & 31.9 & 162 & 3.0 & 0.84 & -30 \\
\hline 6 & 15.2 & 7.28 & 12.1 & 8.49 & 22.5 & 2.1 & 0.73 & +19 \\
\hline 7 & 66.5 & 24.1 & 35.6 & 18.5 & 90.6 & 2.8 & 0.83 & +4 \\
\hline 8 & 3.20 & 1.69 & 3.23 & 4.37 & 4.89 & 1.9 & 0.53 & -120 \\
\hline 9 & 52.3 & 19.0 & 30.4 & 13.2 & 71.3 & 2.8 & 0.84 & -93 \\
\hline 10 & 22.3 & 10.2 & 13.6 & 7.59 & 32.5 & 2.2 & 0.81 & -135 \\
\hline 11 & 60.4 & 13.1 & 36.4 & 16.8 & 73.5 & 4.6 & 0.81 & -70 \\
\hline 12 & 2.06 & 1.16 & 2.06 & 1.53 & 3.22 & 1.8 & 0.68 & -195 \\
\hline 13 & 17.4 & 4.13 & 9.59 & 5.45 & 21.5 & 4.2 & 0.80 & -185 \\
\hline 14 & 4.49 & 2.40 & 4.31 & 2.65 & 6.89 & 1.9 & 0.72 & -95 \\
\hline 15 & 0.71 & 0.29 & 1.76 & 2.25 & 1.00 & 2.4 & 0.31 & -100 \\
\hline Average & & & & & 63.5 & 3.1 & 0.75 & \\
\hline
\end{tabular}

Data for sterols and $E_{\mathrm{h}}$ measured in sediments from the Tan-Shui Estuary.

${ }^{*} r=5 \beta / 5 \beta+5 \alpha=\Sigma$ coprostanol $/(\Sigma$ coprostanol + cholestanol $)$. 


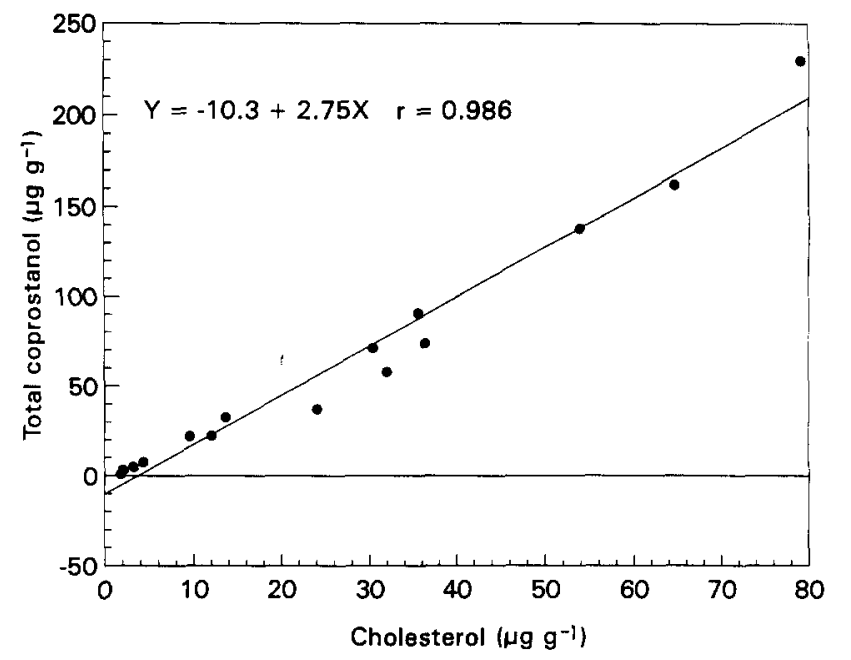

Fig. 4 Plot of total coprostanol vs. cholesterol in sediments from the Tan-Shui Estuary.

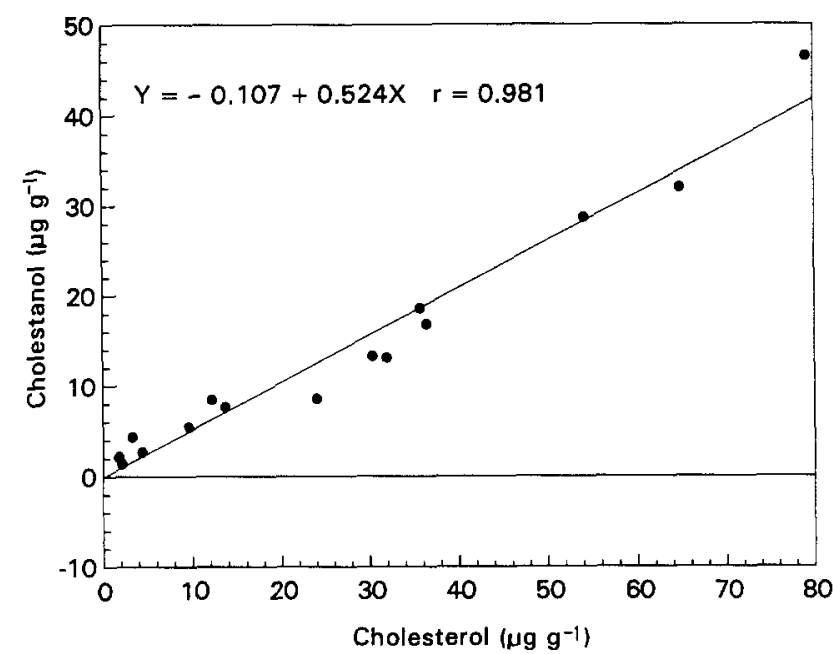

Fig. 5 Plot of cholestanol vs. cholesterol in sediments from the TanShui Estuary.

Eglinton, 1975; Taylor et al., 1981; Nishimura, 1982). It is thought that this relationship has been mediated predominantly by microbial activity under the following conditions: 1 . same degradation rate or no degradation for these three sterols; 2 . anoxicity aiding in better preservation of sterols (Nishimura, 1978; Bartlett, 1987 ) in the sampling area for a very long period of time; 3. the predominant sterol source being from sewage; 4 . the sole process of sterol transformation being microbial activity, etc. It should be noted that the slope of regression lines may vary from one area to another and is characteristic of sediments in a certain area. In highly dynamic systems like estuary and harbour, it would be extremely difficult to calculate a theoretical value to compare with the measured slopes without a range of data such as influx and outflux rates of coprostanol, cholesterol and cholestanol, persistence and duration of anoxicity, knowledge of sediment movement and accumulation rate, species of bacteria, composition and concentration of chemical nutrients, etc.

In the Tan-Shui Estuary, the coprostanol/cholesterol and cholestanol/cholesterol ratios of final effluents (unfiltered) of the sewage outfall are 0.69 and 0.043 , respectively, and those of sediments at varying distances from the sewage outfall are 2.75 and 0.524 (slopes of regression lines, Figs 4 and 5), respectively. The increase in cholestanol (twelve-fold) can be attributed to reduction of cholesterol by bacterial transformation. The increase in coprostanol (four-fold) can be, at least in part, ascribed to bacterial transformation under the reducing condition and should not be considered directly from faecal matter inputs. High levels of coprostanol alone cannot monitor pollution correctly without taking diagenesis into consideration especially in the reducing environment. As a result, interpretation of sewage pollution in sediment should be made with caution. Fortunately, Grimalt et al. (1990) have given a useful index, $5 \beta / 5 \beta+5 \alpha$, for urban sewage monitoring.

We thank Messrs Y. C. Yao and Tony H. J. Chen for assistance in sample collection, and referees for constructive comments. This study was supported by the National Science Council, Republic of China.

Bartlett, P. D. (1987). Degradation of coprostanol in an experimental system. Mar. Pollut. Bull. 18, 27-29.

Brown, R. C. \& Wade, T. L. (1984). Sedimentary coprostanol and hydrocarbon distribution adjacent to a sewage outfall. Water Res. 18 621-632.

Chen, J. C. (1977). Heavy metal distribution in Kaohsiung Harbour sediments. Acta Oceanogr. Taiwanica 7, 44-55.

Churchland, L. M., Kan, G. \& Ages, A. (1982). Variation in faecal pollution indicators through tidal cycles in the Fraser River estuary. Can. J. Microbiol. 28, 239-247.

Dureth, S., Herrmann, R. \& Pecher, K. (1986). Tracing faecal pollution by coprostanol and intestinal bacteria in an ice-covered Finnish lake loaded with both industrial and domestic sewage. Wat. Air Soil Pollut. 28, 131-149.

Eneroth, P., Hellstrom, K. \& Ryhage, R. (1964). Identification and quantification of neutral fecal steroids by gas-liquid chromatography and mass spectrometry: studies of human excretion during two dietary regimens. J. Lipid Res. 5, 245-262.

Gaskell, S. J. \& Eglinton, G. (1975). Rapid hydrogenation of sterols in a contemporary lacustrine sediment. Nature 254, 209-211.

Goodfellow, R. M., Cardoso, J., Eglinton, G., Dawson, J. P. \& Best, G. A. (1977). A faecal sterol survey in the Clyde Estuary. Mar. Pollut. Bull. 8, 272-276.

Grimalt, J. O., Fernandez, P., Bayona, J. M. \& Albaiges, J. (1990). Assessment of fecal sterols and ketones as indicators of urban sewage inputs to coastal waters. Environ. Sci. Technol. 24, 357363.

Hatcher, P. G. \& McGillivary, P. A. (1979). Sewage contamination in the New York Bight. Coprostanol as an indicator. Environ. Sci. Technol. 13, 1225-1229.

Jeng, W. L. \& Han, B. C. (1991). Coprostanol as an indicator of environmental pollution on the western coast of Taiwan. J. Environ. Protect. Soc. ROC 14(1), 38-47.

Karickhoff, S. W., Brown, D. S. \& Scott, T. A. (1979). Sorption of hydrophobic pollutants on natural sediments. Water Res. 13, 241248.

LeBlanc, L. A., Latimer, J. S., Ellis, J. T. \& Quinn, J. G. (1992). The geochemistry of coprostanol in waters and surface sediments from Narragansett Bay. Estuar. Coast. Shelf Sci. 34, 439-458.

McCalley, D. V., Cooke, M. \& Nickless, G. (1980). Coprostanol in Severn Estuary sediments. Bull. Environ. Contam. Toxic. 25, 374381.

McCalley, D. V., Cooke, M. \& Nickless, G. (1981). Effect of sewage treatment on faecal sterols. Water Res. 15, 1019-1025.

Means, J. C., Wood, S. G., Hassett, J. J. \& Banwart, W. L. (1980). Sorption of polynuclear aromatic hydrocarbons by sediments and soils. Environ. Sci. Technol. 14, 1524-1528.

Muller, G., Kanazawa, A. \& Teshima, S. I. (1979). Sedimentary record of faecal pollution in part of Lake Constance by coprostanol determination. Naturwissenschaften 66, 520-522.

Nishimura, M. (1978). Geochemical characteristics of the high reduction zone of stenols in Suwa sediments and the environmental factors controlling the conversion of stenols into stanols. Geochim. Cosmochim. Acta 42, 349-357. 


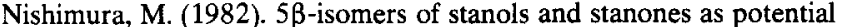
markers of sedimentary organic quality and depositional paleoenvironments. Geochim. Cosmochim. Acta 46, 423-432.

Nishimura, M. \& Koyama, T. (1977). The occurrence of stanols in various living organisms and the behavior of sterols in contemporary sediments. Geochim. Cosmochim. Acta 41, 379-385.

Readman, J. W., Preston, M. R. \& Mantoura, R. F. C. (1986). An integrated technique to quantify sewage, oil and PAH pollution in estuarine and coastal environments. Mar. Pollut. Bull. 17, 298-308.

Simard, R. G., Hasegawa, I., Bandaruk, W. \& Headington, C. E. (1951). Infrared spectrophotometric determination of oil and phenols in water. Analyt. Chem. 23, 1384-1387.

Switzer-Howse, K. O. \& Dutka, B. J. (1978). Fecal Sterol Studies: Samples Processing and Microbial Degradation. National Water Research Institute Scientific Series No. 89. Burlington, Ontario.

Taylor, C. D., Smith, S. O. \& Gagosian, R. B. (1981). Use of microbial enrichments for the study of the anaerobic degradation of cholesterol. Geochim. Cosmochim. Acta 45, 2161-2168.
Tseng, C. M. (1991). Study on speciation of trace metals in sediments M.S. thesis. National Taiwan University.

Van Vleet, E. S., Fossato, V. U., Sherwin, M. R., Lovett, H. B. \& Dolci F (1988). Distribution of coprostanol, petroleum hydrocarbons, and chlorinated hydrocarbons in sediments from canals and coastal waters of Venice, Italy. Org. Geochem. 13, 757-763.

Venkatesan, M. I. \& Kaplan, I. R. (1990). Sedimentary coprostanol as an index of sewage addition in Santa Monica Basin, southern California. Environ. Sci. Technol. 24, 208-214.

Venkatesan, M. I., Ruth, E. \& Kaplan, I. R. (1986). Coprostanols in Antarctic marine sediments: a biomarker for marine mammals and not human pollution. Mar. Pollut. Bull. 17, 554-557.

Venkatesan, M. I. \& Santiago, C. A. (1989). Sterols in ocean sediments: novel tracers to examine habitats of cetaceans, pinnipeds, penguins and humans. Mar. Biol. 102, 431-437.

Yde, M., DeWulf, E., DeMaeyer-Cleempoel, S. \& Quaghebeur, D. (1982). Coprostanol and bacterial indicators of faecal pollution in the Scheldt Estuary. Bull. Environ. Contam. Toxic. 28, 129-134. 